\title{
Novel Urinary Biomarkers in Detecting Acute Kidney Injury, Persistent Renal Impairment and All-cause Mortality following Decongestive Therapy in Acute Decompensated Heart Failure
}

\author{
Frederik H. Verbrugge, M.D. ${ }^{1,2}$, Matthias Dupont, M.D. ${ }^{1}$, Zhili Shao, M.D. Ph.D. ${ }^{3}$, Kevin \\ Shrestha, M.D. ${ }^{3}$, Dhssraj Singh, M.D. ${ }^{4}$, Michael Finucan, B.S. ${ }^{3}$, Wilfried Mullens, M.D. Ph.D. \\ 1,5 , and W.H. Wilson Tang, M.D. ${ }^{3,6}$ \\ ${ }^{1}$ Department of Cardiology, Ziekenhuis Oost-Limburg, Genk, Belgium \\ ${ }^{2}$ Doctoral school for Medicine and Life Sciences, Hasselt University, Diepenbeek, Belgium \\ ${ }^{3}$ Department of Cellular and Molecular Medicine, Lerner Research Institute, Cleveland Clinic, \\ Cleveland, Ohio \\ ${ }^{4}$ University of Kansas Medical Center, Kansas City, Kansas \\ ${ }^{5}$ Biomedical Research Institute, Faculty of Medicine and Life Sciences, Hasselt University, \\ Diepenbeek, Belgium \\ ${ }^{6}$ Department of Cardiovascular Medicine, Heart and Vascular Institute, Cleveland Clinic, \\ Cleveland, Ohio
}

\section{Abstract}

Background-New urinary biomarkers such as neutrophil gelatinase-associated lipocalin (NGAL), kidney injury molecule-1 (KIM-1) and interleukin-18 (IL-18) are proposed to allow a more reliable early diagnosis and prognosis of acute kidney injury (AKI) in acute decompensated heart failure (ADHF). Our aim was to compare the predictive value of urinary NGAL, KIM-1 and IL-18 for the occurrence of AKI, persistent renal impairment and mortality in ADHF.

\begin{abstract}
Methods and Results-Eighty-three patients admitted for ADHF were analyzed. Urinary creatinine (Cr), NGAL, KIM-1 and IL-18 were measured at baseline. Serum Cr was measured daily during the next 4 days and again at outpatient follow-up after 6 months. Mortality data were prospectively collected. Urinary NGAL, KIM-1 and IL-18 were modestly correlated with each other (Spearman's $\rho \unlhd 0.61$ ) and poorly correlated to estimated glomerular filtration rate (eGFR; Spearman's $\rho \$$.28). None predicted AKI defined as a $25 \%$ decrease in eGFR during index hospitalization, but urinary IL-18/Cr was the strongest predictor of persistently elevated serum $\mathrm{Cr} \searrow 0.3 \mathrm{mg} / \mathrm{dL}$ after 6 months compared to baseline (AUC $=0.674 ; \mathrm{p}=0.013$ ). Urinary IL-18 was also associated with all-cause mortality (HR 1.48, 95\% CI 1.16-1.87; $\mathrm{p}=0.001)$.
\end{abstract}

(C) 2013 Elsevier Inc. All rights reserved

Address for correspondence: W.H. Wilson Tang M.D. Department of Cardiovascular Medicine Heart and Vascular Institute, Cleveland Clinic 9500 Euclid Avenue, Desk J3-4 Cleveland, OH 44195, United States of America Phone: (216) 444-2121 / Fax: (216) 445-6165/tangw@ccf.org.

Publisher's Disclaimer: This is a PDF file of an unedited manuscript that has been accepted for publication. As a service to our customers we are providing this early version of the manuscript. The manuscript will undergo copyediting, typesetting, and review of the resulting proof before it is published in its final citable form. Please note that during the production process errors may be discovered which could affect the content, and all legal disclaimers that apply to the journal pertain.

DISCLOSURES All other authors have no relationships to disclose. 
Conclusions-Like urinary NGAL, urinary KIM-1 and IL-18 are relatively modest predictors of AKI in ADHF. Among these novel renal biomarkers examined, further investigations regarding the prognostic value of urinary IL-18 are warranted.

\section{Keywords}

Acute decompensated heart failure; acute kidney injury; biomarkers; outcome

\section{INTRODUCTION}

Changes in serum creatinine $(\mathrm{Cr})$ have been the traditional method to monitor renal function during decongestive therapies in patients presenting with acute decompensated heart failure (ADHF). Worsening renal function (WRF), often defined as a $0.3 \mathrm{mg} / \mathrm{dL}$ rise in $\mathrm{Cr}$, is a common finding in this context ${ }^{1}$. However, apart from structural damage to the nephron (i.e. "kidney injury"), it might reflect impaired renal hemodynamics (i.e. "pre-renal" azotemia), hemoconcentration, or a combination of these. Importantly, those causes of elevated $\mathrm{Cr}$ differ in reversibility and are difficult to discriminate by the Risk, Injury, Failure, Loss of kidney function and End-Stage kidney disease (RIFLE) criteria for acute kidney injury $(\mathrm{AKI})^{2}$. This is probably one of the main reasons why the prognostic impact of WRF, defined as a $\mathrm{Cr}$ change, differs among subgroups of patients with $\mathrm{ADHF}^{3-5}$.

Recently, new biomarkers have been proposed to improve the diagnosis of AKI and differentiate structural renal damage from "pre-renal" insufficiency or hemoconcentration. Neutrophil gelatinase-associated lipocalin (NGAL) is a $25 \mathrm{kDa}$ protein secreted by renal tubular cells, leucocytes, and several other types of epithelial cells in response to ischemic or toxic injury ${ }^{6}$. Because NGAL is normally reabsorbed by the proximal tubules after glomerular filtration, increased urinary NGAL levels reflect impaired proximal reabsorption or increased production in distal nephron segments. On the other hand, kidney injury molecule-1 (KIM-1) is a transmembrane glycoprotein belonging to the immunoglobulin gene superfamily ${ }^{6}$. It is expressed on the apical membrane ciliae of proximal tubules in case of injury, but not in the normal kidney. In addition, interleukin-18 (IL-18) is a proinflammatory cytokine, produced by renal tubular cells and macrophages ${ }^{6}$. IL-18 appears to play a role in apoptosis, ischemia/reperfusion, infection, autoimmune conditions and malignancy. Both urinary NGAL and urinary KIM-1 have been demonstrated to be increased in congestive heart failure, even when estimated glomerular filtration rate (eGFR) is within the normal range, and prior reports have suggested that elevated levels are associated with poor clinical outcomes ${ }^{7}$.

In ADHF patients, we have previously reported a rise in urinary NGAL preceding AKI during hospital admission ${ }^{8}$. However, this rise was only marginal compared with reports from patients with other AKI causes, suggesting only a low degree of renal tubular injury in ADHF. Others have suggested that the combination of urinary NGAL and urinary IL-18 might allow a more reliable early diagnosis and prognosis of $\mathrm{AKI}^{9}$. Yet no study has directly compared the urinary biomarkers NGAL, KIM-1, and IL-18 in a head-to-head manner in the setting of ADHF. Therefore, the aim of the present study was to assess and compare their predictive value for the incidence of AKI, persistent renal impairment and all-cause mortality in patients admitted with ADHF.

\section{METHODS}

\section{Study population}

Patients were eligible for enrollment within $24 \mathrm{~h}$ of presentation. Other inclusion criteria were: (1) age $\geq 18$ years; (2) a planned strategy for treatment with intravenous furosemide 
because of clinical evidence of congestion. Exclusion criteria were: (1) a concurrent diagnosis of an acute coronary syndrome; (2) cardiogenic shock or need for inotropes; (3) a history of cardiac transplantation and/or ventricular assist devices; (4) renal replacement therapy at any time point during or before the index hospitalization; (5) exposure to nephrotoxic agents (i.e. contrast dye); (6) urinary tract infection or bacteremia.

\section{Study design}

The Cleveland Clinic Institutional Review Board approved the study and all subjects provided written informed consent. After enrollment, demographics, clinical history, relevant co-morbid conditions, pharmacological therapy, documented left ventricular ejection fraction and a previous serum creatinine value from the last outpatient visit ( $\leq 3$ months) were collected. Urine and venous blood samples were obtained at the time of admission for baseline measurements, including serum cystatin C, plasma B-type natriuretic peptide (BNP), as well as urinary NGAL, urinary KIM-1, and urinary IL-18. Absolute urinary biomarker levels were subsequently corrected for urinary creatinine and ratios expressed per gram of creatinine. Cr measurements were repeated daily during the next 4 days and again after 6 months of follow-up during an outpatient visit as part of routine clinical care. eGFR was calculated according to the Chronic Kidney Disease Epidemiology Collaboration (CKD-EPI) formula ${ }^{10}$. Treatment regimens, including timing, dosage, and route of diuretic therapy, were at the discretion of the treating physician independent of the renal or urinary biomarkers or BNP levels.

\section{Biomarker assays}

All laboratory analyses were performed with investigators blinded to cardio-renal indices and clinical outcome data. Serum cystatin $\mathrm{C}$ levels were determined with a particleenhanced immunoturbidimetric immunoassay on the Architect ci8200 platform (Abbott Laboratories, Abbott Park, IL). Briefly, latex particles are coated with anti-human cystatin C antibody (Diazyme Laboratories, Poway CA) and agglutinate with cystatin $\mathrm{C}$ present in patients' sample. The analytical range of this assay spans $0.05 \mathrm{mg} / \mathrm{L}$ to the highest calibration point. Intra- and inter-assay coefficients are $3 \%$ and $6 \%$, respectively. BNP levels were measured using the same immunoassay platform. Urinary NGAL levels were measured by an enzyme-linked immunosorbent assay (Cat. No. KIT 036, BioPorto Diagnostics, Gentofte Denmark). The minimum detection limit of the assay was $4 \mathrm{pg} / \mathrm{mL}$. Intra-and inter-assay coefficients of variation were $1.1 \%$ and $3.2 \%$, respectively, at $65 \mathrm{ng} /$ mL. KIM-1 was measured by the Quantikine Human TIM-1 Immunoassay (R\&D Systems Inc., Minneapolis, MN) with a functional sensitivity of $\$ 0.046 \mathrm{ng} / \mathrm{mL}$ and a total coefficient of variation $<8 \%$. The human IL-18 ELISA Kit (Medical \& Biological Laboratories, Woburn MA) was used to assess urinary IL-18. This assay has a functional sensitivity of $12.5 \mathrm{pg} / \mathrm{mL}$ with a total coefficient of variation of $<11 \%$.

\section{Study end-points}

First, we assessed the correlation between urinary biomarker levels with each other, as well as with eGFR. Second, we compared the accuracy of each biomarker to predict (1) AKI, defined as a $225 \%$ decrease in eGFR during day $1-5$; (2) persistent renal impairment, defined as persistently elevated Cr levels ( $\searrow 0.3 \mathrm{mg} / \mathrm{dL}$ ) after 6 months compared to baseline; and (3) all-cause mortality.

\section{Statistical analysis}

Continuous variables were expressed as mean \pm standard deviation if normally distributed or otherwise by median [interquartile range (IQR)]. Normality was assessed by the ShapiroWilk statistic. Categorical variables were expressed as percentages. The student's $t$-test, 
Mann-Whitney $U$ test, Fisher's exact test and Pearson's $\chi^{2}$-test were used when appropriate to compare between groups. Correlations were assessed using Spearman's $\rho$. Statistical significance was set at a 2-tailed probability level of $<0.05$. Receiver-operated characteristic curve analysis was used to compare urinary biomarkers as predictors for AKI, and persistent renal impairment, respectively. The Cox proportional hazards model was used to calculate the hazard ratio (HR) with corresponding $95 \%$ confidence interval (95\% CI) for all-cause mortality. We included all baseline characteristics and urinary biomarker levels at admission in a univariate model. All statistics were performed using IBM® SPSS $®$ (version 20.0) for Windows.

\section{RESULTS}

\section{Study population}

We enrolled 90 patients who fulfilled inclusion and exclusion criteria. Seven patients were subsequently excluded because of missing data. In one patient, measurement of urinary biomarkers was not done as the urinary sample was discarded accidently. In another patient, only one serum creatinine measurement (baseline) was available and therefore the end-point of AKI could not be determined. Finally, KIM-1 measurements were lacking in 5 other patients. Those 7 patients had similar baseline characteristics compared to the study population analyzed. All of them were alive at the end of follow-up. Inclusion of these patients in the analyses rendered similar results. Therefore, the final analysis encompasses 83 patients with complete data. Baseline characteristics and pharmacological therapy of the study population are summarized in Table 1 . Baseline Cr was $1.32 \mathrm{mg} / \mathrm{dL}(1.03-2.19 \mathrm{mg} /$ $\mathrm{dL}$ ), corresponding to an eGFR of $57 \pm 29 \mathrm{~mL} / \mathrm{min} / 1.73 \mathrm{~m}^{2}$. Serum cystatin $\mathrm{C}$ was $2.14 \pm 0.80$ $\mathrm{mg} / \mathrm{dL}$, which corresponded to the same eGFR. In contrast, median (IQR) Cr was $1.14 \mathrm{mg} /$ $\mathrm{dL}(0.99-1.48 \mathrm{mg} / \mathrm{dL})$ at the moment of the last outpatient evaluation preceding the index hospitalization, corresponding to an eGFR of $65 \pm 26 \mathrm{~mL} / \mathrm{min} / 1.73 \mathrm{~m}^{2}$.

\section{Correlation between urinary biomarkers and eGFR}

We observed only moderate correlations between different urinary biomarkers and each other (Table 2). Overall, biomarker levels were relatively low at the time of admission: urinary NGAL was $12.3 \mathrm{ng} / \mathrm{mL}(5.6-27.4 \mathrm{ng} / \mathrm{mL})$ or $2.0 \mathrm{ng} / \mathrm{g}_{\mathrm{Cr}}\left(0.6-7.5 \mathrm{ng} / \mathrm{g}_{\mathrm{Cr}}\right)$; urinary KIM-1 was $0.68 \mathrm{ng} / \mathrm{mL}(0.17-1.78 \mathrm{ng} / \mathrm{mL})$ or $0.30 \mathrm{ng} / \mathrm{g}_{\mathrm{Cr}}\left(0.07-1.02 \mathrm{ng} / \mathrm{g}_{\mathrm{Cr}}\right)$; and urinary IL-18 was $26.37 \mathrm{pg} / \mathrm{mL}(10.97-46.56 \mathrm{pg} / \mathrm{mL})$ or $7.05 \mathrm{pg} / \mathrm{g}_{\mathrm{Cr}}\left(2.90-11.82 \mathrm{pg} / \mathrm{g}_{\mathrm{Cr}}\right)$. Both absolute urinary biomarker levels and values corrected for $\mathrm{Cr}$ were poorly correlated to eGFR (Table 3).

\section{Prediction of AKI with urinary biomarkers}

Fourteen patients (17\%) experienced AKI during the first 5 days of the index hospitalization. Patients who developed AKI had a lower baseline blood urea nitrogen compared to patients who did not $(28 \pm 14 \mathrm{mg} / \mathrm{dL}$ versus $45 \pm 14 \mathrm{mg} / \mathrm{dL}$, respectively; $\mathrm{p}=0.007$ ), but other baseline characteristics were similar. Figure 1 shows the evolution of the eGFR over time according to the development of AKI. Patients with AKI tended to have an improvement in renal function at follow-up $\left(\triangle \mathrm{eGFR}=+6 \pm 25 \mathrm{~mL} / \mathrm{min} / 1.73 \mathrm{~m}^{2} ; \mathrm{p}=0.386\right)$. In contrast, patients without AKI experienced a non-significant decrease in eGFR at follow-up $\left(\triangle \mathrm{eGFR}=-2 \pm 23 \mathrm{~mL} / \mathrm{min} / 1.73 \mathrm{~m}^{2} ; \mathrm{p}=0.421\right)$. Comparing all urinary biomarkers with or without creatinine adjustment, none had adequate sensitivity/specificity to predict AKI (Figure 2). The length of hospital stay was 11 days (8-15 days) in patients with versus 9 days (5-19 days) in patients without AKI ( $\mathrm{p}=0.860$ for the difference). 


\section{Prediction of persistent renal impairment with urinary biomarkers}

After 6 months, 25 patients ( $31 \%$ ) had a persistently elevated $\mathrm{Cr}$ level ( $\searrow 0.3 \mathrm{mg} / \mathrm{dL}$ ) compared to baseline. Those patients had significantly higher baseline BNP levels $[1,150$ $\mathrm{pg} / \mathrm{mL}$ (792-2145 pg/mL)] compared to patients without persistent renal impairment [809 $\mathrm{pg} / \mathrm{mL}$ (370-1408 pg/mL); $\mathrm{p}=0.043$ for the difference between groups]. Other baseline characteristics were similar among both groups. Figure 3 shows the evolution of the eGFR over time according to the presence of persistent renal impairment. Patients with persistent renal impairment had a gradual and significant decline in eGFR during the index hospitalization $\left(\triangle \mathrm{eGFR}=-6 \pm 12 \mathrm{~mL} / \mathrm{min} / 1.73 \mathrm{~m}^{2} ; \mathrm{p}=0.028\right)$. In contrast, patients without persistent renal impairment had no significant change in eGFR $(\Delta \mathrm{eGFR}=+2 \pm 16 \mathrm{~mL} / \mathrm{min} /$ $1.73 \mathrm{~m}^{2} ; \mathrm{p}=0.478$ ). Urinary IL-18, especially when corrected for creatinine, was the only urinary biomarker with acceptable sensitivity/specificity to predict persistent renal impairment (Figure 4). At an optimal cut-off value of $7 \mathrm{pg} / \mathrm{g}_{\mathrm{Cr}}$ (comparable to the median value in the population), urinary IL-18 had $68 \%$ sensitivity and $60 \%$ specificity to predict persistent renal impairment.

\section{All-cause mortality}

During $7 \pm 4$ months of follow-up, 31 patients died (37\%). The results of univariate analysis for baseline characteristics to predict all-cause mortality are presented in Table 4 . Only urinary IL-18 (HR 1.48, 95\% CI 1.16-1.87; p=0.001) was significantly associated with allcause mortality. In addition, persistent renal impairment (HR 2.23, 95\% CI 1.07-4.66; $\mathrm{p}=0.032)$ but not AKI (HR 1.37, 95\% CI 0.56-3.36; $\mathrm{p}=0.488)$ was significantly correlated to all-cause mortality.

\section{DISCUSSION}

The key finding of this prospective cohort study of patients admitted with ADHF is that novel urinary biomarkers that reflect renal tubular injury are generally poor predictors of inhospital AKI as defined by $\mathrm{Cr}$ levels. Only urinary IL-18/Cr had a modest predictive value for persistent renal impairment after 6 months of follow-up, which was more consistently associated with all-cause mortality than AKI. In contrast, urinary NGAL and urinary KIM-1 did not reliably predict persistent renal impairment or all-cause mortality.

Our group and others have identified the association between elevated serum NGAL levels and the occurrence of WRF in patients with ADHF ${ }^{11}$. Even though earlier work has implied that serum and urinary NGAL levels as well as eGFR are correlated in patients with ischemic heart failure ${ }^{12}$, new evidence has suggested that serum and urinary NGAL represent different aspects of the nephron's function. While higher serum NGAL correlates well to reduced glomerular filtration function, urinary NGAL is more like a marker of impaired natriuresis and diuresis in the setting of ADHF ${ }^{13}$. Although it has been well described that urinary NGAL levels are higher in heart failure patients than in healthy volunteers, correlations with other markers of renal tubular damage (i.e. urinary albumin excretion) are very poor and the rise of urinary NGAL during decongestive treatment is very modest, even in case of WRF, when compared with other AKI causes ${ }^{8,14,15}$. Indeed, in most patients admitted for ADHF, urinary NGAL levels remain well below the cut-off proposed to predict AKI after cardiac surgery, which is $50-213 \mathrm{ng} / \mathrm{mL}^{8,16,17}$. There is similar but less evidence regarding KIM-1 as a marker for tubular injury in ADHF. Urinary KIM-1 levels are higher in heart failure patients compared with controls, even when eGFR is within the normal range, but still levels remain well below the proposed cut-off of $7 \mathrm{ng} / \mathrm{g} \mathrm{Cr}$ for predicting $\mathrm{AKI}$ 7, 14, 18, 19 . Our findings confirm that urinary NGAL, urinary KIM-1, and urinary IL-18 are generally lower in patients who present with ADHF than those reported in the literature with AKI, which suggests that AKI in ADHF is likely due to other causes than 
structural tubular damage. Indeed, hemodynamics that determine renal blood flow (both renal perfusion and venous congestion) show a better correlation with renal function and make a stronger plead for a phenotype of "pre-renal" azotemia $20,21$.

\section{Clinical importance of the current study}

Our study adds several new findings to the current literature for these novel renal biomarkers. First, for the first time the patterns of urinary NGAL, urinary KIM-1, and urinary IL-18 are compared in a head-to-head manner in the setting of ADHF and their predictive value for AKI and short-term mortality is assessed. We demonstrated that those urinary biomarkers correlate only moderately with each other, suggesting that they reflect different functional aspects of the nephron or the fact that they have a wide range of analytical variability. All the biomarkers demonstrated relatively poor correlations with eGFR, which could be expected from specific biomarkers of renal tubular damage. Second, we analyzed an end-point of persistent renal impairment. It has been clearly demonstrated from a sub-analysis of the Efficacy of Vasopressin Antagonism in Heart Failure Outcome Study with Tolvaptan (EVEREST) that post-discharge WRF or AKI has a much stronger prognostic value than WRF or AKI during hospitalization ${ }^{22}$. Indeed we showed that eGFR tended to improve in patients with AKI defined as a $\geq 25 \%$ decrease in eGFR during day $1-5$ of the index hospitalization, although this remained associated with a (non-significant) $37 \%$ increase in all-cause mortality. In contrast, persistent renal impairment, defined as a persistently elevated $\operatorname{Cr}(\searrow 0.3 \mathrm{mg} / \mathrm{dL})$ after 6 months compared to baseline increased allcause mortality more than twofold, a finding that was statistically significant. This is reassuring for those that experience WRF during hospitalization whereby achieving recovery of renal function may occur beyond hospitalization. Third, our data suggest that urinary IL-18 might be a better predictor for persistent renal impairment and all-cause mortality when compared to urinary NGAL or urinary KIM-1. Urinary IL-18/Cr at a cut-off similar to the median $\left(7 \mathrm{ng} / \mathrm{g}_{\mathrm{Cr}}\right)$ had a modest $68 \%$ sensitivity and $60 \%$ specificity to predict persistent renal impairment after 6 months.

Parikh et al. were the first to suggest that urinary IL-18 might be a useful early diagnostic marker for AKI in the intensive care unit ${ }^{23}$. Previously, it had been showed in animal models that IL-18 mediates ischemic acute tubular necrosis and that impaired IL-18 processing protects caspase-1-deficient mice against deterioration of renal impairment 24,25 . This active involvement in the pathophysiology of ischemic acute tubular necroses, the type of tubular injury one would most expect from impaired hemodynamics in ADHF, might explain why urinary IL-18 performed better than urinary NGAL and urinary KIM-1 in our population. Moreover, the well-known correlation between serum IL-18 and myocardial dysfunction, atherogenesis, plaque rupture, and ischemia-reperfusion injury might further strengthen its value as a prognostic marker in ADHF ${ }^{26-29}$. In contrast, both urinary NGAL and urinary KIM-1 were not significantly associated with all-cause mortality. Therefore, further studies in the role of urinary IL-18 in ADHF are warranted.

\section{Study limitations}

Our results should be interpreted in the light of some study limitations. First, our renal endpoints were based on serum creatinine measurements, which are influenced by age, gender, ethnicity, muscle mass, diet and tubular secretion apart from glomerular filtration ${ }^{30}$. However, we calculated eGFR, using the most accurate formula currently available (CDKEPI) ${ }^{10}$. Further, baseline serum creatinine and calculated eGFR were validated against serum cystatin $\mathrm{C}$ levels, which yielded an equal eGFR. Second, we obtained urinary biomarkers only at the moment of admission. Therefore, we cannot report changes over time, which might enhance the performance of those biomarkers to predict AKI or persistent renal impairment. Third, there was no clinical or histological information available about 
underlying intrinsic renal disease as "gold standard" for AKI. Fourth, follow-up was only limited in time, but $\searrow 6$ months for every patient, precluding conclusions about the value of the urinary biomarkers for long-term prognosis. Also, in the absence of standardization of treatment protocol but instead according to the preferences of the treating physician, differences in the use, type and dosages of diuretics before or after baseline measurements may have influenced the results. Fifth, it should be noted that our population was predominantly male with a fair proportion of heart failure with preserved ejection fraction and relatively preserved baseline renal function. Finally, our study had a limited sample size and therefore our findings should be considered hypothesis-generating which asks for confirmation.

\section{CONCLUSIONS}

Like urinary NGAL, urinary KIM-1 and urinary IL-18 are relatively modest predictors of AKI in ADHF. Among these novel renal biomarkers examined, further investigations regarding the prognostic value of urinary IL-18 are warranted.

\section{Acknowledgments}

None

Grants and supports: This study was supported in part by the National Institutes of Health R01HL103931 and the Cleveland Clinic Clinical Research Unit of the Case Western Reserve University CTSA (UL1TR 000439). Dr. Dupont is supported by a research grant from the Belgian American Educational Foundation (BAEF). Dr. Tang has received research support from Abbott Laboratories.

\section{REFERENCES}

1. Forman DE, Butler J, Wang Y, Abraham WT, O'Connor CM, Gottlieb SS, et al. Incidence, predictors at admission, and impact of worsening renal function among patients hospitalized with heart failure. J Am Coll Cardiol. 2004; 43:61-7. [PubMed: 14715185]

2. Mehta RL, Kellum JA, Shah SV, Molitoris BA, Ronco C, Warnock DG, et al. Acute Kidney Injury Network: report of an initiative to improve outcomes in acute kidney injury. Crit Care. 2007; 11:R31. [PubMed: 17331245]

3. Testani JM, Chen J, McCauley BD, Kimmel SE, Shannon RP. Potential effects of aggressive decongestion during the treatment of decompensated heart failure on renal function and survival. Circulation. 2010; 122:265-72. [PubMed: 20606118]

4. Testani JM, Cappola TP, Brensinger CM, Shannon RP, Kimmel SE. Interaction between loop diuretic-associated mortality and blood urea nitrogen concentration in chronic heart failure. $\mathrm{J} \mathrm{Am}$ Coll Cardiol. 2011; 58:375-82. [PubMed: 21757114]

5. Testani JM, Kimmel SE, Dries DL, Coca SG. Prognostic importance of early worsening renal function after initiation of angiotensin-converting enzyme inhibitor therapy in patients with cardiac dysfunction. Circ Heart Fail. 2011; 4:685-91. [PubMed: 21903907]

6. Cruz DN, Goh CY, Haase-Fielitz A, Ronco C, Haase M. Early biomarkers of renal injury. Congest Heart Fail. 2010; 16(Suppl 1):S25-31. [PubMed: 20653708]

7. Damman K, Masson S, Hillege HL, Maggioni AP, Voors AA, Opasich C, et al. Clinical outcome of renal tubular damage in chronic heart failure. Eur Heart J. 2011; 32:2705-12. [PubMed: 21666249]

8. Dupont M, Shrestha K, Singh D, Awad A, Kovach C, Scarcipino M, et al. Lack of significant renal tubular injury despite acute kidney injury in acute decompensated heart failure. Eur J Heart Fail. 2012; 14:597-604. [PubMed: 22505396]

9. Parikh CR, Mishra J, Thiessen-Philbrook H, Dursun B, Ma Q, Kelly C, et al. Urinary IL-18 is an early predictive biomarker of acute kidney injury after cardiac surgery. Kidney Int. 2006; 70:199_ 203. [PubMed: 16710348]

10. Levey AS, Stevens LA, Schmid CH, Zhang YL, Castro AF 3rd, Feldman HI, et al. A new equation to estimate glomerular filtration rate. Ann Intern Med. 2009; 150:604-12. [PubMed: 19414839] 
11. Aghel A, Shrestha K, Mullens W, Borowski A, Tang WH. Serum neutrophil gelatinase-associated lipocalin (NGAL) in predicting worsening renal function in acute decompensated heart failure. $\mathrm{J}$ Card Fail. 2010; 16:49-54. [PubMed: 20123318]

12. Poniatowski B, Malyszko J, Bachorzewska-Gajewska H, Malyszko JS, Dobrzycki S. Serum neutrophil gelatinase-associated lipocalin as a marker of renal function in patients with chronic heart failure and coronary artery disease. Kidney Blood Press Res. 2009; 32:77-80. [PubMed: 19287180]

13. Shrestha K, Shao Z, Singh D, Dupont M, Tang WH. Relation of systemic and urinary neutrophil gelatinase-associated lipocalin levels to different aspects of impaired renal function in patients with acute decompensated heart failure. Am J Cardiol. 2012; 110:1329-35. [PubMed: 22835414]

14. Damman K, Van Veldhuisen DJ, Navis G, Vaidya VS, Smilde TD, Westenbrink BD, et al. Tubular damage in chronic systolic heart failure is associated with reduced survival independent of glomerular filtration rate. Heart. 2010; 96:1297-302. [PubMed: 20659949]

15. Damman K, van Veldhuisen DJ, Navis G, Voors AA, Hillege HL. Urinary neutrophil gelatinase associated lipocalin (NGAL), a marker of tubular damage, is increased in patients with chronic heart failure. European journal of heart failure. 2008; 10:997-1000. [PubMed: 18804416]

16. Mishra J, Dent C, Tarabishi R, Mitsnefes MM, Ma Q, Kelly C, et al. Neutrophil gelatinaseassociated lipocalin (NGAL) as a biomarker for acute renal injury after cardiac surgery. Lancet. 2005; 365:1231-8. [PubMed: 15811456]

17. Wagener G, Brentjens TE. Renal disease: the anesthesiologist's perspective. Anesthesiol Clin. 2006; 24:523-47. [PubMed: 17240605]

18. Jungbauer CG, Birner C, Jung B, Buchner S, Lubnow M, von Bary C, et al. Kidney injury molecule-1 and N-acetyl-beta-D-glucosaminidase in chronic heart failure: possible biomarkers of cardiorenal syndrome. European journal of heart failure. 2011; 13:1104-10. [PubMed: 21846754]

19. Han WK, Waikar SS, Johnson A, Betensky RA, Dent CL, Devarajan P, et al. Urinary biomarkers in the early diagnosis of acute kidney injury. Kidney Int. 2008; 73:863-9. [PubMed: 18059454]

20. Damman K, van Deursen VM, Navis G, Voors AA, van Veldhuisen DJ, Hillege HL. Increased central venous pressure is associated with impaired renal function and mortality in a broad spectrum of patients with cardiovascular disease. J Am Coll Cardiol. 2009; 53:582-8. [PubMed: 19215832]

21. Mullens W, Abrahams Z, Francis GS, Sokos G, Taylor DO, Starling RC, et al. Importance of venous congestion for worsening of renal function in advanced decompensated heart failure. $\mathrm{J} \mathrm{Am}$ Coll Cardiol. 2009; 53:589-96. [PubMed: 19215833]

22. Blair JE, Pang PS, Schrier RW, Metra M, Traver B, Cook T, et al. Changes in renal function during hospitalization and soon after discharge in patients admitted for worsening heart failure in the placebo group of the EVEREST trial. Eur Heart J. 2011; 32:2563-72. [PubMed: 21785107]

23. Parikh CR, Abraham E, Ancukiewicz M, Edelstein CL. Urine IL-18 is an early diagnostic marker for acute kidney injury and predicts mortality in the intensive care unit. J Am Soc Nephrol. 2005; 16:3046-52. [PubMed: 16148039]

24. Melnikov VY, Ecder T, Fantuzzi G, Siegmund B, Lucia MS, Dinarello CA, et al. Impaired IL-18 processing protects caspase-1-deficient mice from ischemic acute renal failure. J Clin Invest. 2001; 107:1145-52. [PubMed: 11342578]

25. Melnikov VY, Faubel S, Siegmund B, Lucia MS, Ljubanovic D, Edelstein CL. Neutrophilindependent mechanisms of caspase-1- and IL-18-mediated ischemic acute tubular necrosis in mice. J Clin Invest. 2002; 110:1083-91. [PubMed: 12393844]

26. Mallat Z, Henry P, Fressonnet R, Alouani S, Scoazec A, Beaufils P, et al. Increased plasma concentrations of interleukin-18 in acute coronary syndromes. Heart. 2002; 88:467-9. [PubMed: 12381634]

27. Mallat Z, Heymes C, Corbaz A, Logeart D, Alouani S, Cohen-Solal A, et al. Evidence for altered interleukin 18 (IL)-18 pathway in human heart failure. FASEB journal : official publication of the Federation of American Societies for Experimental Biology. 2004; 18:1752-4. [PubMed: 15371332]

28. Chalikias GK, Tziakas DN, Kaski JC, Kekes A, Hatzinikolaou EI, Stakos DA, et al. Interleukin-18/ interleukin-10 ratio is an independent predictor of recurrent coronary events during a 1-year 
follow-up in patients with acute coronary syndrome. Int J Cardiol. 2007; 117:333-9. [PubMed: 16859776]

29. Furtado MV, Rossini AP, Campani RB, Meotti C, Segatto M, Vietta G, et al. Interleukin-18: an independent predictor of cardiovascular events in patients with acute coronary syndrome after 6 months of follow-up. Coron Artery Dis. 2009; 20:327-31. [PubMed: 19593889]

30. Stevens LA, Levey AS. Measurement of kidney function. Med Clin North Am. 2005; 89:457-73. [PubMed: 15755462] 


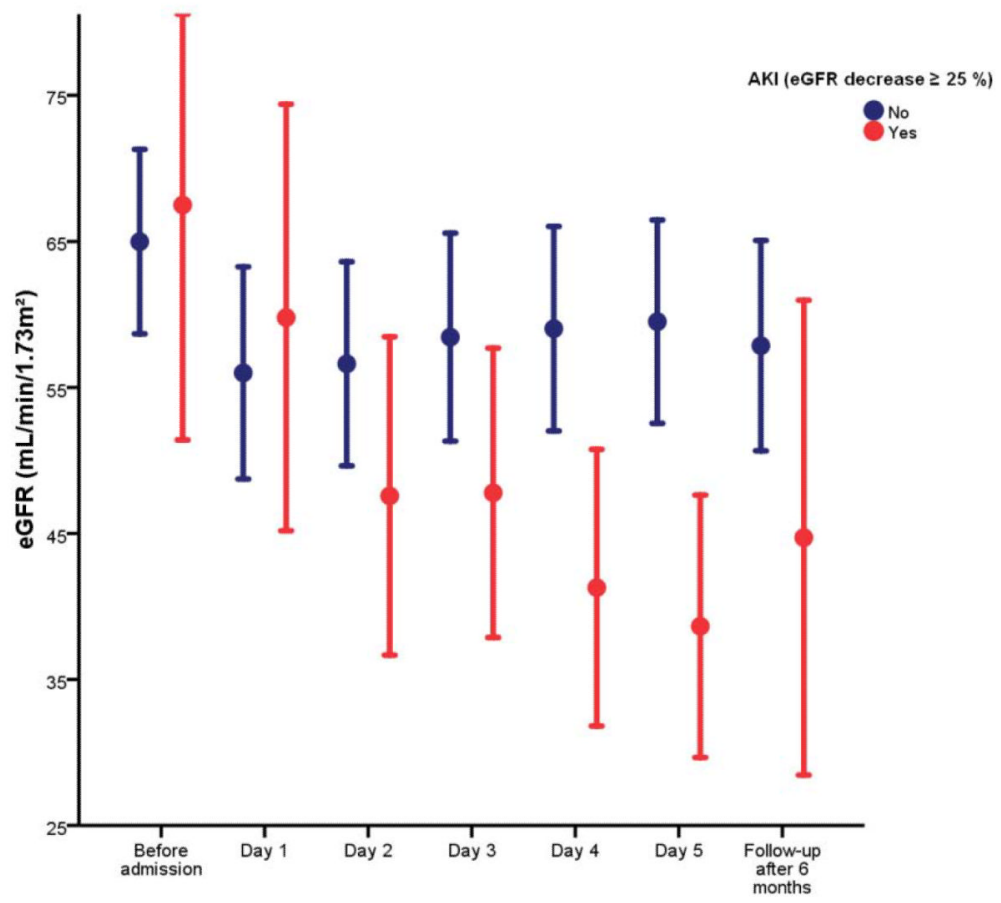

Figure 1.

Evolution of estimated glomerular filtration rate (eGFR) during hospitalization for acute decompensated heart failure (ADHF) and at follow-up according to the development of acute kidney injury (AKI) defined as $\geq 25 \%$ decrease in eGFR. 


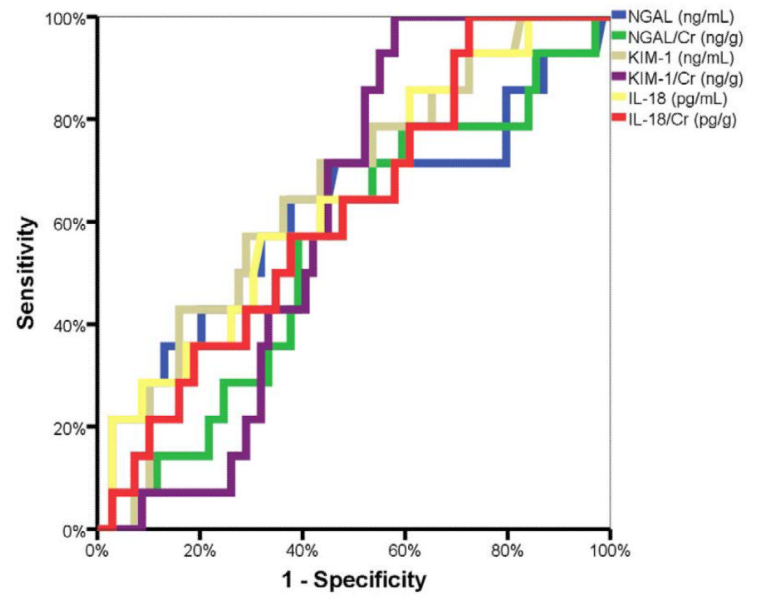

\begin{tabular}{lll}
\hline NGAL & AUC $=0.615(0.434-0.796)$ & $p=0.177$ \\
NGAL /Cr & AUC $=0.541(0.382-0.700)$ & $p=0.627$ \\
KIM-1 & AUC $=0.658(0.511-0.805)$ & $p=0.064$ \\
KIM-1/Cr & AUC $=0.607(0.488-0.725)$ & $p=0.210$ \\
IL-18 & AUC $=0.643(0.489-0.798)$ & $p=0.092$ \\
IL-18/Cr & AUC $=0.618(0.471-0.765)$ & $p=0.166$ \\
\hline
\end{tabular}

Figure 2.

Receiver-operated characteristic (ROC) curve analysis for urinary biomarkers to predict AKI. 


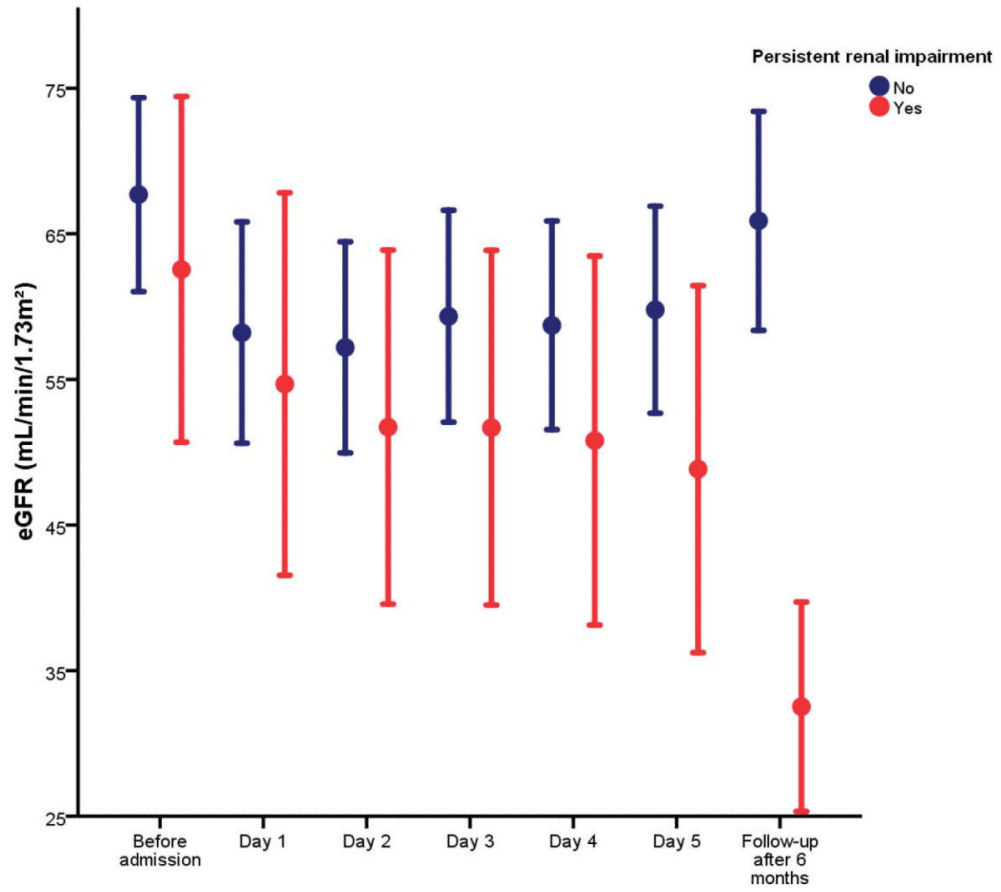

Figure 3.

Evolution of eGFR during hospitalization for ADHF and at follow-up in patients with versus without persistent renal impairment defined as $\searrow 0.3 \mathrm{mg} / \mathrm{dL}$ increase in serum creatinine after 6 months compared to baseline. 


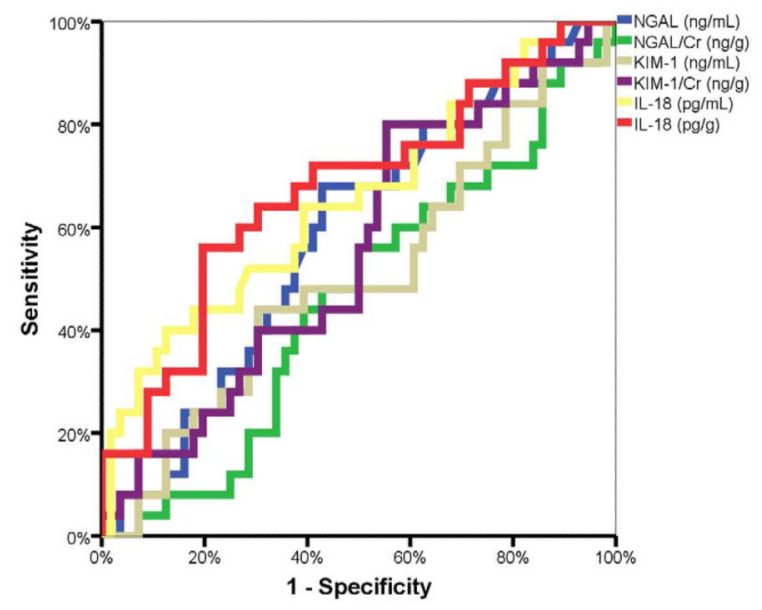

\begin{tabular}{lll}
\hline NGAL & AUC $=0.584(0.453-0.715)$ & $\mathrm{p}=0.228$ \\
NGAL /Cr & $\mathrm{AUC}=0.461(0.327-0.594)$ & $\mathrm{p}=0.574$ \\
$\mathrm{KIM}-1$ & $\mathrm{AUC}=0.504(0.365-0.643)$ & $\mathrm{p}=0.951$ \\
$\mathrm{KIM}-1 / \mathrm{Cr}$ & $\mathrm{AUC}=0.556(0.423-0.690)$ & $\mathrm{p}=0.419$ \\
$\mathrm{IL-18}$ & $\mathrm{AUC}=0.652(0.519-0.786)$ & $\mathrm{p}=0.029$ \\
$\mathrm{IL}-18 / \mathrm{Cr}$ & $\mathrm{AUC}=0.674(0.543-0.805)$ & $\mathrm{p}=0.013$ \\
\hline
\end{tabular}

Figure 4.

ROC curve analysis for urinary biomarkers to predict persistent renal impairment. 
Table 1

Baseline characteristics and pharmacological therapy of the study population $(n=83)$

\begin{tabular}{|c|c|}
\hline Baseline characteristics & \\
\hline Age (years) & $64 \pm 15$ \\
\hline \multicolumn{2}{|l|}{ Gender } \\
\hline Male & $73 \%$ \\
\hline Female & $27 \%$ \\
\hline \multicolumn{2}{|l|}{ Ethnicity } \\
\hline White & $68 \%$ \\
\hline Black & $31 \%$ \\
\hline Asian & $1 \%$ \\
\hline Body mass index $\left(\mathrm{kg} / \mathrm{m}^{2}\right)$ & $30 \pm 9$ \\
\hline Hypertension & $68 \%$ \\
\hline Diabetes mellitus & $43 \%$ \\
\hline Ischemic etiology of heart failure & $40 \%$ \\
\hline Left ventricular ejection fraction (\%) & $31 \pm 17$ \\
\hline Left ventricular ejection fraction $>40 \%$ & $28 \%$ \\
\hline Plasma brain natriuretic peptide (pg/mL) & $881(450-1,899)$ \\
\hline Atrial fibrillation & $37 \%$ \\
\hline Chronic obstructive pulmonary disease & $15 \%$ \\
\hline Blood urea nitrogen $(\mathrm{mg} / \mathrm{dL})$ & $43 \pm 25$ \\
\hline \multicolumn{2}{|l|}{ Renal function - KDOQI class $*$} \\
\hline $\mathrm{I}\left(\mathrm{eGFR} \unrhd 90 \mathrm{~mL} / \mathrm{min} / 1.73 \mathrm{~m}^{2}\right)$ & $19 \%$ \\
\hline II (eGFR $\left.60-89 \mathrm{~mL} / \mathrm{min} / 1.73 \mathrm{~m}^{2}\right)$ & $41 \%$ \\
\hline IIIa (eGFR $45-59 \mathrm{~mL} / \mathrm{min} / 1.73 \mathrm{~m}^{2}$ ) & $12 \%$ \\
\hline IIIb (eGFR 30-44 mL/min/1.73m²) & $19 \%$ \\
\hline IV (eGFR $15-29 \mathrm{~mL} / \mathrm{min} / 1.73 \mathrm{~m}^{2}$ ) & $7 \%$ \\
\hline $\mathrm{V}\left(\mathrm{eGFR}<15 \mathrm{~mL} / \mathrm{min} / 1.73 \mathrm{~m}^{2}\right)$ & $1 \%$ \\
\hline \multicolumn{2}{|l|}{ Pharmacological therapy } \\
\hline Angiotensin-converting enzyme inhibitor & $34 \%$ \\
\hline Angiotensin II receptor blocker & $12 \%$ \\
\hline$\beta$-blocker & $65 \%$ \\
\hline Mineralocorticoid receptor antagonist & $29 \%$ \\
\hline Digoxin & $24 \%$ \\
\hline Loop diuretic & $81 \%$ \\
\hline Vasodilator & $29 \%$ \\
\hline Aspirin & $58 \%$ \\
\hline Statin & $43 \%$ \\
\hline Calcium channel blocker & $13 \%$ \\
\hline
\end{tabular}

KDOQI, Kidney Disease Outcomes Quality Initiative; eGFR, estimated glomerular filtration rate by the Chronic Kidney Disease Epidemiology Collaboration (CKD-EPI) formula based on the last serum creatinine value available preceding the index admission 
Table 2

Spearman's correlation between urinary biomarkers head to head

\begin{tabular}{lccccc}
\hline & NGAL/Cr & KIM-1 & KIM-1/Cr & IL-18 & IL-18/Cr \\
\cline { 2 - 6 } NGAL & $\rho=0.75$ & $\rho=0.42$ & $\rho=-0.23$ & $\rho=0.30$ & $\rho=0.05$ \\
& $\mathrm{p}<0.001$ & $\mathrm{p}<0.001$ & $\mathrm{p}=0.035$ & $\mathrm{p}=0.006$ & $\mathrm{p}=0.637$ \\
NGAL/Cr & & $\rho=0.23$ & $\rho=-0.57$ & $\rho=-0.24$ & $\rho=-0.56$ \\
& & $\mathrm{p}=0.035$ & $\mathrm{p}<0.001$ & $\mathrm{p}=0.033$ & $\mathrm{p}<0.001$ \\
KIM-1 & & $\rho=0.61$ & $\rho=0.49$ & $\rho=0.18$ \\
& & & $\mathrm{p}<0.001$ & $\mathrm{p}<0.001$ & $\mathrm{p}=0.108$ \\
KIM-1/Cr & & & & $\rho=0.61$ & $\rho=0.57$ \\
& & & & $\mathrm{p}<0.001$ & $\mathrm{p}<0.001$ \\
IL-18 & & & & $\rho=0.79$ \\
\end{tabular}

Cr, serum creatinine; IL-18, interleukin-18; KIM-1, kidney injury molecule-1; NGAL, neutrophil gelatinase-associated lipocalin 
Table 3

Spearman's correlation between urinary biomarkers and estimates of glomerular filtration rate

\begin{tabular}{lcccc}
\hline & Serum Cr & eGFR $_{\text {Cr }}$ & Serum Cystatin C & eGFR $_{\text {CysC }}$ \\
\cline { 2 - 5 } NGAL & $\rho=0.17$ & $\rho=-0.22$ & $\rho=0.28$ & $\rho=-0.28$ \\
& $\mathrm{p}=0.122$ & $\mathrm{p}=0.048$ & $\mathrm{p}=0.012$ & $\mathrm{p}=0.012$ \\
NGAL/Cr & $\rho=0.27$ & $\rho=-0.28$ & $\rho=0.26$ & $\rho=-0.26$ \\
& $\mathrm{p}=0.015$ & $\mathrm{p}=0.009$ & $\mathrm{p}=0.023$ & $\mathrm{p}=0.022$ \\
KIM-1 & $\rho=-0.03$ & $\rho=-0.01$ & $\rho=0.07$ & $\rho=-0.08$ \\
& $\mathrm{p}=0.790$ & $\mathrm{p}=0.925$ & $\mathrm{p}=0.523$ & $\mathrm{p}=0.467$ \\
KIM-1/Cr & $\rho=-0.21$ & $\rho=0.19$ & $\rho=-0.15$ & $\rho=0.14$ \\
& $\mathrm{p}=0.055$ & $\mathrm{p}=0.078$ & $\mathrm{p}=0.190$ & $\mathrm{p}=0.207$ \\
IL-18 & $\rho=-0.26$ & $\rho=0.23$ & $\rho=-0.15$ & $\rho=0.15$ \\
& $\mathrm{p}=0.020$ & $\mathrm{p}=0.040$ & $\mathrm{p}=0.198$ & $\mathrm{p}=0.192$ \\
IL-18/Cr & $\rho=-0.19$ & $\rho=0.14$ & $\rho=-0.01$ & $\rho=0.01$ \\
& $\mathrm{p}=0.080$ & $\mathrm{p}=0.224$ & $\mathrm{p}=0.925$ & $\mathrm{p}=0.909$ \\
\hline
\end{tabular}

Cr, serum creatinine; IL-18, interleukin-18; KIM-1, kidney injury molecule-1; NGAL, neutrophil gelatinase-associated lipocalin 


\section{Table 4}

Significant predictors of all-cause mortality in univariate analysis

\begin{tabular}{lcc}
\hline & $\begin{array}{c}\text { Univariate HR } \\
(\mathbf{9 5} \% \mathbf{C I})\end{array}$ & P-value \\
\cline { 2 - 3 } & $0.56(0.27-1.19)$ & 0.131 \\
Male gender & $1.26(0.90-1.77)$ & 0.186 \\
Ejection fraction (\%) & $1.28(0.93-1.75)$ & 0.132 \\
Baseline plasma BNP (pg/mL) & $1.37(0.97-1.93)$ & 0.072 \\
Baseline serum Cystatin C (mg/L) & $1.26(0.97-1.64)$ & 0.079 \\
Baseline urinary NGAL (ng/mL) & $1.29(0.98-1.71)$ & 0.072 \\
Baseline urinary KIM-1 (ng/mL) & $1.48(1.16-1.87)$ & 0.001 \\
Baseline urinary IL-18 (pg/mL) & & \\
\hline
\end{tabular}

BNP, brain natriuretic peptide; uNGAL, urinary neutrophil gelatinase-associated lipocalin; uKIM-1, urinary kidney injury molecule-1; uIL-18, urinary interleukin-18

HR for continuous variables expressed per standard deviation change 